\title{
Summary of Ammunition Support Studies under Information Condition
}

\author{
Guan Jicheng ${ }^{1}$ and Li Liangchun ${ }^{2}$ \\ ${ }_{1}^{1}$ Ordnance Engineering College, Shijiazhuang, China \\ ${ }^{2}$ Ordnance Technology Institute, Shijiazhuang, China
}

\begin{abstract}
The informatization demand of military ammunition support was analysed. The research status of ammunition containerization, RFID technology and asset visualization were introduced. The existent problems were pointed out and the future development was predicted.
\end{abstract}

\section{Introduction}

The essence of ammunition support is to send the right amount of ammunition to the designated locations in a timely manner by the operation of moving ammunition to complete. In the process of ammunition support, related departments need to know in real-time that what arrived, what has been sent, where is the need, where do the things delivered arrive and what do a point have. The information transfer is slow and lagging seriously rely on traditional methods of information processing. Army ammunition support is experiencing the paradigm shift from the "rough estimates" to "accurately support". It is necessary to use modern information technology to complete the work such as munitions identification, checking, statistics, monitoring, tracking and management quickly and accurately, achieving asset visualization and process controllable of ammunition support, improving rapid response capability, meeting the demand for military general ammunition supply guarantee in local wars under the information condition [1], [2]. Related research relates to three areas, ammunition containerization, RFID technology and asset visualization.

\section{Research status}

From the mid-90s of the last century, mainly by Ordnance Technology Institute under the guidance of the headquarters to carry out the overall planning and toplevel design on ammunition support system of army forces, divisions, groups and other troops at all levels. Explicitly stating the guiding principle that base on reality and face the future, combine the peacetime and wartime and wartime based, overall optimizing and system matching, focus on quality and strive for efficiency, overall planning and step by step. Proposing the system construction goal of quick and rapid reaction, flexible and reliable operation, safe and efficient operations, timely and accurate supply, sustained and effective guarantee.

\subsection{Formatting ammunition containerization areas}

Ammunition containerization means based on the principles of modern military logistics, forming a certain number of bulk ammunition into a larger transport guarantee unit with advanced container technology to adapt our military mechanization and informatization leapfrog development and meet the demand for ammunition fast supply guarantee in integrated joint operations.

Lujun et al proposed the implementation of infantry ammunition matching packaging and carried out the feasibility analysis by analysing the effect of packaging on ammunition supply support and demand characteristics of infantry ammunition packaging. They described the current application and future development of ammunition packaging in US military supply support. Then they discussed the significance of the army infantry using ammunition matching packaging from three aspects. Studying at infantry ammunition matching packaging, which is in accord with the new military strategic policy, will help to improve the ability of troops to accomplish diverse military tasks. Li liangchun [3] et al analysed the positive effects of containerization on ammunition Support from three aspects and introduced three packaging method. According to the characteristics of army ammunition support, they put forward three packaging proposals, developing pallet container, paying high attention to bracket container and moderately achieving container bags. Gao Xinbao [4] et al analysed the impact of ammunition support on army combat effectiveness in terms of ammunition quality, timeliness and accuracy of the supply. And they analysed the impact of packaging structure and format on support capabilities of ammunition from aspects which are security, transport security mode and information support. In order to improve the ability of ammunition support, they proposed to improve and perfect the ammunition packaging architecture, building information security platform and 
expanding ammunition packaging security function. $\mathrm{Li}$ Tianpeng [5] et al analysed modern warfare demand for ammunition support in two aspects, ammunition storage environment effects (atmospheric environment, mechanical environment, electromagnetic environment) and ammunition supply support efficacy (transport links, information networks). They introduced the status of existing military ammunition packaging and designed and analysed ammunition container model on the protection function, supply function and information function of the ammunition container. Zhao Fanggeng [6] et al analysed the status of military supplies containerization and discussed the strategies of strengthening military supplies containerization, they suggested formulating an overall plan of supplies containerization, establishing a scientific management mode of container, developing advanced container and handing equipment, improving the information level of supplies containerization. Chen Jingsheng et al analyzed the current situation of military ammunition packaging, then pointing out that there are still some problems such as poor protective performance, inconvenient to use and low degree of standardization. Finally they proposed several countermeasures and suggestions for how to carry out ammunition packaging serialization.

\subsection{RFID technology areas}

Radio Frequency Identification is one of the multitudinous automatic identification technologies. It can work normally without any physical contact. RFID technology uses coupling or propagation of space electromagnetic waves for communications and it can work on the movement of objects or the immobile for data collection [7]. RFID technology started late in China which entered China for the first time in 1994. Whether RFID chip or RFID technology the research is far behind the developed countries and the level of logistics informatization is relatively low. In recent years, with economic development, China has made great progress in RFID standards development and application promotion [8]-[11].

The army also has a very clear demand for applications of RFID technology, the introduction of RFID technology in military logistics management can adapt to military logistics requirements in wartime and peacetime. The General Logistics Department and General Armament Department set up a large number of research projects in RFID and the RFID are also gradually popularized in military logistics. Yan Fengbin [12] et al introduced the basic concepts of packaging and RFID and put forward three kinds of ways of packaging. Aiming at the task-supporting way, they described the writing and revision process of identification data in four stages from supplies packaging to materials consumed. Through the application of RFID technology, it will be solved that military supplies packed identify is inferior in automaticity and difficult to modify. The automated identification of various types of packaging information will be achieved and with modification of the write terminal the precise and timely support will be realized.
Cai Junfeng [13] et al elaborated the application of RFID in ammunition supply support from two aspects, ammunition storage and supply security. They explained the issues that the application of RFID faced, such as technology, standardization, confidentiality, safe use, environmental compatibility and storage. Aiming at the application of RFID in ammunition supply support, they proposed three countermeasures, strengthen the research development, unified technical standards and steadily promote pilot applications. They pointed out that informatization is the trends of ammunition support. With the development of military technology and improvement of ammunition security system the army will eventually solve the challenge that the application of RFID faced. RFID technology will play an important role in achieving the army supply support informatization. Xie Guanyou [14] et al introduced the application status of RFID technology in the military field, highlighting the related applications in the US military. By analyzing the feasibility of RFID technology application, they pointed out that hardware and software conditions are ready for extending RFID technology application on ammunition container unit and present the detailed workflow of RFID-based ammunition containerization security. Wang Wei [15] et al introduced the functional requirements of automatic identification system from the environment, life and recognition angles. Then they studied the RFID system solution from three aspects, the electronic tag choice, reader choice, software structure and requirements. Li Hongwei, et al carried out the requirement analysis on ammunition containerized security management system based on RFID technology, expounding the realization of system design from four aspects of the system block diagram, electronic tag selection, the data read and write acquisition and data sheet design. Problems the system faced with and the key technology it needs have also been analysed. They proposed the system has a good promotion prospects and application value, and has been successfully applied in an army ammunition fine management.

\subsection{Asset visualization areas}

Lin Congguang [16] et al discussed how to advance the construction of logistics assets visualization (LAV) in seven aspects, such as improving and perfecting the strategic planning of LAV, creating the architecture of LAV, promoting logistics system, accelerating integration development, strengthening integrated management and building the core competitiveness. Liu Yanhua [17] et al pointed out that the army total asset visibility system require achieving three visualization, supplies in use and inventory visualization, assets in transport visualization and assets in dealing with visualization. They described the related visualization system to be built. They also elaborated the development approach of Total Asset Visibility, such as adhering to the unified leadership and unified planning, insisting on unified development and unified standards, insisting on open architecture and coordinating stable structure and the balance of environmental change. Yang Zhengshu [18] 
et al analyzed the army current problems of military supplies support and introduced the advantages of Total Asset Visibility. They said there are four problems of Total Asset Visibility construction need to solve: construction of military logistics network information platform, construction of materials information source data acquisition system, construction of military material transport information tracking and control system and development of common materials management software system. They also described the techniques of each problem and pointed out several considerations of Total Asset Visibility. Liu Hua'an [19] et al discussed the guiding ideology of the army JTAV construction, the construction target (resource visualization, security integration, rapid support, accurately control) and JTAV construction principles. They designed JAVA technology system reference model and JAVA system architecture reference model. Xuan Zhaolong et al introduced ammunition packaging informatization in brief and pointed out the key technology involved are automatic identification and location tracking. They analysed the composition and operation of ammunition packaging information system, explaining how to achieve better ammunition packaging information from four aspects of information standardization, electronic tags, reading and writing equipment and management systems, putting forward that ammunition packaging design should be grounded in becoming the carrier of information network and the realization of ammunition support whole process visualization should base on establishing visual system in each theater.

\section{Problems and trends}

Overall, the military ammunition support still has the following issues under the new period of informatization warfare conditions:

- The lesser extent of army ammunition containerization is greatly reducing the efficiency of ammunition guarantee.

- RFID technology has just started and standardization has not been unified.

- The information security technology study of ammunition support process is not deep enough.

The military ammunition support should seize the opportunity of informatization, strengthen the construction of ammunition containerization and strengthen the research and application of RFID technology and related information systems, forming the standards and specifications in line with the actual needs of the army in order to achieve the information automatic identification and rapid transfer of ammunition support as soon as possibly [20].

\section{Conclusions}

Modern wars under conditions of informatization require efficient ammunition storage and supply security. The achievement of informatization is the development trend of ammunition support through information technology.
RFID technology with its unique characteristics of noncontact identification has broad prospects for development in ammunition storage management and visible support of ammunition supply. Although currently there are still some problems and challenges in the application of RFID technology in military ammunition storage security, with the development of technology and the improvement of military ammunition storage security system, the problem of the application of RFID in ammunition storage security will definitely be satisfactorily resolved. And RFID technology will play an important role in the army ammunition support.

\section{References}

1. Li Liangchun, Xie Guanyou, Pu Zhigang, Tang Bo. Research on Visible Support of General Ammunition Packaging Unit Based on RFID [J]. Logistics SciTech, (2009), 02:92-95

2. Tian Runliang, Yin Peng, Ren Jie, Zhai Junwei. Application of Container Ro-Ro Pallets in Military Material Containerization Support [J]. Containerization, (2010), 04:24-26

3. Li Liangchun, Yu Chengguo, Jiao Yang, Xie Guanyou. Development of Ammunition Container Packaging for the New Military Reform [J]. Packaging Engineering, (2007), 11:8-10

4. Gao Xinbao,Li Tianpeng. Analysis of Influences and Countermeasures of Ammunition Packaging on Army Support Capability [J]. Packaging Engineering, (2011), 23:154-156

5. Li Tianpeng,Fu Xiaozhong,Xu Haitao Study on Ammunition Integrated Packaging Mode of Storage and Transportation Integration $[\mathrm{J}]$. Packaging Engineering, (2011), 23:23-25

6. Zhao Fanggeng, Shi Xiaoyan, Strategy Analysis of Enhancing Military Material Containerization Construction [J]. Packaging Engineering, (2013), 09:127-130

7. Zhang Jun,Mei Zhonghao.Logistics packaging and application Based on the Internet of Things Technology $[\mathrm{J}]$. Packaging Engineering, (2014), 17:135-139

8. Luo Yanping.Research on Military Logistics Supports Technology RFID Based [D]. Chongqing University, (2014)

9. Zhang Xuechun, Chen Yu, Zhou Dingru, Li Jialiang. Discussion on Application of RFID in Military Product Package [J]. Packaging Engineering, (2007), 12:66-67

10. Pang Ming. Internet of Things Bar-code Technology and RFID Technology [M]. Beijing, China Supplies, (2011)

11. Zhang Meng. Discuss the Intelligent packaging and RFID technology [J]. Guangdong print, (2011), 05:47-49

12. Yan Fengbin, Liu Zhenyu, Zhang Baohua. Application of RFID Technology in the Identification and Recognition of Military Material Packaging [J]. Value Engineering, (2015), 03:160161 
13. Cai Junfeng, Gao Xinbao, Fu Xiaozhong. Research on Key Problems and Countermeasures of RFID Application in Ammunition Reserve and Supply Support $[\mathrm{J}]$. Logistics Engineering and Management, (2012), 12:63-65

14. Xie Guanyou, Li Liangchun, Xing Yang. The Application of RFID Technology in Ammunition Containerization Support [J]. Journal of Sichuan Ordnance, (2009), 02:101-103

15. Wang Wei, Xuan Zhaolong, Cheng Ze, Li Jingming, Zhang Xiaoyi. Automatic Recognition System Lised in Ammunition Storage and Transportation Shelter Based on RFID [J]. Packaging Engineering, (2014), 11:91-95

16. Lin Congguang, Chu Wei. Actively Promoting the Construction of Military Logistical Assets Visualization [J]. Journal of Logistical Engineering University, (2006), 04:74-79
17. Liu Yanhua, Sun Shaofang, Zhang Lianfeng. The Development Conception and Approach of Army Total Asset Visualization System [J]. Military Economic Research, (2012), 06:40-41

18. Yang Zhengshu, Yan Hongchao. Study on Military Logistics Total Asset Visualization [J]. Journal of Chongqing University of Technology, (2010), 11:4045

19. Liu Hua'an, Yi Mingyi. The Preliminary Exploration of Army Joint Total Asset Visibility System Construction $[\mathrm{J}]$. Automated Command and Computer, (2007), 02:40-44

20. Zhao Jimin, Chen Wenge, Guo Baohua, Liu Zhenhua. Requirement Analysis of Military packaging Based on Modern Military Logistics [A]. The Thirteenth National Packaging Engineering Conference Proceedings, (2010):4 